ISSN 0001-6002/2001/43/1/3-4

Acta Médica Costarricense,(C2001

Colegio de Médicos y Cirujanos

\title{
La Nueva "Regla Pediátrica" y los Ensayos Clínicos Controlados
}

Diariamente muchos padres en sus hogares, se ven obligados a suministrar a sus hijos medicamentos para padecimientos diversos cuya farmacocinética, seguridad y eficacia no han sido sólidamente establecidas en pacientes pediátricos. Es muy frecuente que medicamentos que podrían ser beneficiosos para los niños, contengan en su etiquetado informaciones como: "Este producto no debe utilizarse en niños menores de dos años porque la seguridad en este grupo de edad no ha sido establecida", "Por el momento, no se recomienda el uso de estas tabletas en niños menores de 6 años de edad", "La seguridad y efectividad de este medicamento en pediatría no ha sido establecida". Esta situación real y cotidiana, induce a que muchos médicos y padres, por necesidades especificas de salud se vean obligados a usar medicamentos no autorizados en niños, sin que estas "pruebas individuales" estén protegidas por la infraestructura ético-científica de un ensayo clínico controlado y sin que estas experiencias aisladas beneficien a la colectividad pediátrica.

Gran cantidad de fármacos que son imprescindibles para el manejo de los principales padecimientos que aquejan a los niños en la actualidad, como por ejemplo antidepresivos, anticonvulsivantes, analgésicos, antialérgicos y antihipertensivos, entre otros, carecen de la información científica rigurosa que debe desarrollarse para permitir un uso seguro y eficaz en niños, particularmente en los más pequeños.

En los Estados Unidos de Norteamérica, del total de 41,000 ensayos clínicos controlados con medicamentos en curso en la actualidad, solamente 200 corresponden a estudios que potencialmente podrían permitir el uso de nuevos fármacos en pacientes pediátricos. Esta realidad ha colocado a los niños en una posición de desventaja con relación a los adultos, haciendo más lenta su posibilidad de acceso a terapias más modernas y efectivas y obligándolos a tomar presentaciones de medicamentos (tabletas, cápsulas, grageas) diseñadas para tratar adultos pero de difícil dosificación e ingesta por parte de los niños. En vista de lo anterior es que en varios foros internacionales a los niños se les ha llamado "huérfanos terapéuticos".

Todo ensayo clínico controlado debe realizarse en estricto apego a la protección de los sujetos humanos que se fundamenta en tres premisas básicas:

a. El respeto por los derechos del individuo,

b. La obligación de proteger al individuo de risego innecesario, c. La justicia en la distribución de los riesgos y beneficios de la investigación.

Estos principios deben cumplirse con particular observancia en los niños por ser éstos una población especialmente vulnerable. Sin embargo el principio ético de justicia distributiva en investigación clínica, probablemente no ha sido equitativo en la distribución de los recursos mundiales destinados a mejorar el arsenal terapéutico pediátrico, en relación con su contraparte en los adultos. Existe un imperativo moral de estudiar formalmente medicamentos en niños de manera que se les garantice un acceso igualmente expedito y seguro que el que tienen los pacientes adultos. La salud de los niños exige la realización de ensayos clínicos controlados con medicamentos. El crecimiento, la diferenciación y la maduración del organismo de los niños, puede alterar la farmacocinética, respuesta orgánica final y el grado de toxicidad a diferentes drogas en las diversas edades pediátricas: recién nacidos, infantes, niños y adolescentes. Los niños no son "adultos chiquitos" y por lo general las experiencias farmacológicas con los adultos no pueden extrapolarse a la edad pediátrica.

Con base en estos antecedentes, la Agencia Federal de Alimentos, Drogas y Cosméticos de los Estados Unidos de Norteamérica (FDA) promulgó, en Diciembre de 1998, una regla en que solicita a las compañías que manufacturan medicamentos la realización de los estudios científicos pertinentes para que los mismos contengan en sus instrucciones la información necesaria para su utilización en pacientes pediátricos, enfatizando que se deben cubrir desde los recién nacidos hasta los adolescentes. A partir de marzo del presente año, esta información será requerida por la FDA para aprobar el uso y comercialización de nuevos fármacos. Es más, en algunos casos de medicamentos prioritarios para el tratamiento de padecimientos pediátricos que ya están disponibles en el mercado, pero que no cuentan con indicaciones de dosificación ni presentaciones adecuadas, se está exigiendo también que se llene tal requisito.

Obviamente, hay algunos medicamentos que están exentos de cumplir la "Regla Pediátrica de la FDA" tales son los siguientes:

1. Aquellos en que hay evidencia preliminar sólida de que el medicamento es inefectivo o inseguro en todos los pacientes pediátricos 
2. Aquellos en que los estudios en niños son imposibles o altamente imprácticos dado que el número de pacientes candidatos a beneficiarse con el medicamento es extremadamente pequeño o de gran dispersión geográfica.

3. Aquellos en que intentos previos para desarrollar una formulación pediátrica han fallado.

Sin embargo, estas excepciones requieren evaluación individual y son raras. Adicionalmente y como un estímulo para el desarrollo adecuado de medicamentos en pediatría, la "Regla Pediátrica de la FDA" incluye un incentivo de comercialización exclusiva durante seis meses para aquellas compañías que inviertan sus esfuerzos científicos y recursos económicos, para generar la información necesaria y formulaciones óptimas para el uso de diversos tratamientos en niños de diferentes edades.
La promulgación de esta regla ha sido considerada una victoria para la Academia Americana de Pediatría y para múltiples asociaciones y fundaciones de padres, voluntarios y niños aquejados por diversas enfermedades en todo el mundo.

Olga Arguedas Arguedas

Unidad de Bioética e Investigación

Hospital Nacional de Niños

“Dr. Carlos Saénz Herrera”

Centro de Ciencias Médicas de la CCSS

Edgar Mohs Villalta

Hospital Nacional de Niños

"Dr. Carlos Saénz Herrera"

Centro de Ciencias Médicas de la CCSS 